\title{
Birth of second twin 27 hours after the birth of first
}

Rani Jha, Sheela Verma

Janaki Medical College Teaching Hospital, Janakpur

\begin{abstract}
We hereby report a case of retained second twin presenting with vertex which was delivered vaginally after 27 hours from the first birth, without any complication in 25 years old $G_{2} P_{1} L_{1} A 0$ detailing that such obstetric events can be smoothly handled.
\end{abstract}

Keywords: retained second twin, both vertex presentation, obstetric complication in twins.

\section{Introduction}

In 1880 , the phenomenon of delayed delivery of second twin was first described as a coincidental event. ${ }^{1}$ Over the past decade many tocolytics, drugs and cervical encirclage are being used in order to delay the birth of second twin for increasing the chances of its survival, especially in preterm twin pregnancy. ${ }^{2,3}$ Impact of such procedures in later life is still unclear. ${ }^{4,5}$

\section{Case}

A 25 years old woman $\mathrm{G}_{2} \mathrm{P}_{1} \mathrm{~L}_{1} \mathrm{~A} 0$ presented to the obstetric ward of Janakpur Zonal Hospital, Dhanusha from a nearby village on $10^{\text {th }}$ January 2007 at 10.30 AM. She was worried as there was no placental expulsion after the delivery of a live healthy baby girl one day ago ( $9^{\text {th }}$ January, 2007 at about 8.00 AM).

The size of uterus had remained large and thinking of retention of one or more fetus the untrained birth attendant had advised, to go to zonal hospital. She could attend hospital only after 26 hours due to transportation difficulty.

On examination, she was not hypertensive and had BP of 120/80 mm of $\mathrm{Hg}$. There was no pallor or edema. Per abdominal examination showed a uterus of 36 week size. The fetus was lying longitudinally with cephalic presentation having FHR 148/minute. Uterine contraction was mild. Vaginal examination showed the first newborn baby wrapped in some old cloth but attached to the shriveled cord. Cervical Os was $7 \mathrm{~cm}$ dilated and cervix was $100 \%$ effaced. Membrane was intact and head was at " 0 " station.

First baby was separated after clamping and cutting the cord. Its weight was $1.5 \mathrm{~kg}$.Baby was referred to the Pediatrician for further management.

Maternal blood was sent for hemoglobin and blood group. Anticipating a normal vaginal delivery labour was augmented by adding 5 units of oxytocin in 5\% dextrose drip. Artificial rupture of membrane (ARM) was done and the liquor was clear. Patient had a smooth course of labour and a baby girl weighing $2300 \mathrm{Gms}$ was born at 11.25 AM with an Apgar score of 8 and 10 .

Post delivery period remained uneventful. Both the babies were found to be normal and were discharged on third day of delivery along with mother.

\section{Comment}

Delayed delivery of second twin is sometimes attempted in selected multifetal pregnancies when uterine contractions cease after the first delivery. In our case the delay in the delivery of second twin was spontaneous with a favorable outcome, though in many studies the outcome for second twin has not been favorable. This may be because of binovular twins and having separate placenta. ${ }^{4}$

Correspondence

Dr. Rani Jha, $M D$,

Consultant Obstetrician and Gynecologist, JZH, Janaki Medical College Teaching Hospital, Janakpur

Email: ranijha555@hotmail.com, 


\section{Reference}

1. Carson JL: Twins born with interval of fourtyfour days. BMJ1880 ; 1: 242.

2. Jun Zhang, Brady Hamilton, Joyce Martin, Ann Trumble. Delayed interval delivery and infant survival: A population-based study. American Journal of Obstetrics and Gynecology 2004; 191: $470-6$.

3. Trivedi AN, Gillett WR. The retained twin/triplet following preterm delivery -an analysis of the literature. Aust NZ J Obstet Gynaecol 1998; 38: 461-5.

4. Farkouh LJ, Sabin ED, Heyborne KD, Lindsay G, Porreco RP. Delayed-interval delivery: extended series from a single maternal-fetal medicine practice. Am J Obstet Gynecol 2000; 183: 1499503.

5. Fayad S, Bongain A, Holhfeld P, Janky E, DurandReville M, Ejnes L. Delayed delivery of second twin: a multicentre study of 35 cases. Eur J Obstet Gynecol Reprod Biol 2003; 109:16-20. 